\title{
DIVERSIDADE E EQUIDADE DE GÊNERO, NOS INSTITUTOS DE OMBUDSMAN/ OUVIDORIA NO BRASIL, É UMA REALIDADE?
}

\author{
Elaine Regina Terceiro dos Santos ${ }^{1}$ \\ Maria Regina Momesso ${ }^{2}$
}

\begin{abstract}
Resumo
O presente artigo reflete e atenta para a diversidade e o quanto ela é presente nos institutos de Ombudsman/Ouvidoria, que, no Brasil, tiveram como bases o Código de Defesa do Consumidor em 1990, a criação da Fundação Procon e a criação da Associação Brasileira de Ombudsman/Ouvidores em 1995, assim como os aparatos legais das agências e entidades de regulação do mercado, que determinaram em instâncias públicas e privadas sua implantação. Sabe-se que muitas ações têm sido realizadas, observa-se no entanto que a gestão de pessoas e equipes ainda sente grandes dificuldades quando se trata da gestão da diversidade, quase sempre pela falta de conhecimento das "vozes" dos cidadãos ou pela ausência de um sistema de escuta que leve em consideração a forma como o sujeito se constitui dentro das corporações, como ele dimensiona o pessoal com o profissional e o social e vice-versa. Ou seja, há falta de educação formal dos modos de existência, de ética e governabilidade de si para com o outro dentro das corporações para que seja possível trabalhar com os sujeitos na sua forma de ler, interpretar e se expressar dentro do ambiente de trabalho. Para que essa educação formal se faça, as autoras sugerem um projeto de pesquisa sobre o tema nos institutos de Ombudsman/Ouvidoria no Brasil, de forma quantitativa e qualitativa. A partir da análise dos resultados obtidos, far-se-á a elaboração de e-book educacional sobre diversidade e equidade de gênero, bem como a elaboração de curso presencial sobre educação sexual formal para Ombudsman/Ouvidores.
\end{abstract}

Palavras-chave: Ouvidoria. Diversidade. Equidade. Gênero.

\section{DOI:10.37814/2594-5068.2019v2.p97-106}

1 Graduada em Psicologia na FMU. Mestranda no Programa de Mestrado em Educação Sexual. Unesp, Araraquara/ SP. (elaine.terceiro@atento.com)

2 Graduada em Letras. Mestre em Comunicação. Doutora em Linguística (Analista de Discurso). Professora, Doutora e Pesquisadora do PPG em Educação Escolar e em Educação Sexual. Unesp, Araraquara. Líder do Grupo de Pesquisa Gesteld vinculado ao CNPq (www.gesteld.com) do CTI/FEB/UNESP, Bauru, SP. (regina.momesso@unesp.br) 


\section{Abstract}

This article reflects and attentive to diversity and how it is present in Ombudsman institutes, based, in Brazil, on the 1990 Consumer Protection Code, the creation of the Procon Foundation and the creation of the Brazilian Association of Ombudsmen in 1995, as well as the legal apparatus of agencies and regulators of the market, which determined in public and private instances its implementation. It is known that many actions have been carried out, however, it is observed that still the management of people and teams still feels great difficulties when it comes to the management of diversity, almost always this is due to the fact of not knowing the "voices" of the citizens or for lack of a system of listening that takes into account how the subject is constituted within the corporations, how he dimension the personnel with the professional and the social and vice versa. That is, there is the lack of a formal education of the modes of existence, of an ethics and governability of oneself with the other within the corporations, which can work with the subjects in their way of reading, interpreting and expressing themselves within the environment of work. For this formal education to be done, the authors suggest a research project on the subject in the Ombudsman Institutes in Brazil, in a quantitative and qualitative way. Based on the analysis of the results obtained, an educational e-book on gender diversity and equity will be elaborated, as well as the preparation of a face-to-face course on formal sex education for Ombudsmen.

Keywords: Ombudsman. Diversity. Equity. Gender. 


\section{INTRODUÇÃO}

A Ouvidoria é para todos? O instituto de Ombudsman/Ouvidoria tem em seu corpo de funcionários representantes de minorias (LGBTs, Mulheres, Negros, PCDs)? O Ombudsman/Ouvidor está preparado para mediar, dirimir e recomendar ações organizacionais na diversidade que atendam às demandas e expectativas dos cidadãos?

Refazendo a história da Ouvidoria até chegarmos às respostas das questões acima, vamos à sua origem ligada à figura do Ombudsman, que surgiu em 1809 na Suécia. A Ouvidoria é uma "[...] imitação distorcida do instituto denominado Ombudsman" (MEDAUAR, 1993, p. 54), que seria o "advogado do cidadão" perante o Estado. Sua missão era verificar o cumprimento das leis e a tutela dos direitos e garantias individuais, fiscalizando a atividade da Administração Pública.

Em 1916, a Finlândia e, em 1946, a Dinamarca instituíram também o Ombudsman. A Suécia, em 1967, na Reforma Constitucional, avançou e criou o Ombudsman dos Consumidores, o Ombudsman para Liberdade Econômica e o Ombudsman da Imprensa.

No Brasil, a criação desse mecanismo é recente. Em 1986, por decreto presidencial, instituiu-se o cargo de Ouvidor-Geral da Previdência. Em 1989, o jornal Folha de São Paulo designou o primeiro Ombusdsman da imprensa brasileira.

Em 1990, a Lei 8.078, que dispõe sobre a proteção do consumidor (Código de Defesa do Consumidor), bem como a criação da Fundação Procon - SP, pela Lei n 9.192, de 23 de novembro de 1995, e Decreto $n^{\circ} 41.170$, de 23 de setembro de 1996, que tem como missão principal equilibrar e harmonizar as relações entre consumidores e fornecedores, assim como a fundação da Associação Brasileira de Ouvidores/Ombudsman em 16 de março de 1995, foram as bases percussoras para que agências e entidades de regulação do mercado criassem resoluções determinando em instâncias públicas e privadas o instituto de Ouvidoria, solidificando ao longo dos anos o papel do Ouvidor no Brasil, o fortalecimento da voz do cidadão na relação de consumo e o estabelecimento da oferta de consumo mais consciente por parte das empresas e prestadores de serviços.

Nas últimas décadas, em paralelo à ascensão da Ouvidoria no Brasil, movimentos identitários também ganharam espaço na agenda estratégica das organizações dentro do bojo da governança corporativa, são exemplos deles o Instituto Ethos, o Fórum de Empresas e Direitos LGBT+, o Movimento Mulher 360, a Coalização para a Equidade Racial e de Gênero, ONU Mulheres, entre outros, condição que desperta para a inclusão desse mesmo cidadão, que ora consome, como sujeito de diálogo nessa nova sociedade, exigindo novo patamar de relacionamento com as empresas e órgãos dos setores, uma vez que mais consciente de seus direitos. Como consequência, houve o despertar para o saber de si e do outro e evidenciam-se nos discursos públicos ou privados os vieses inconscientes, problematiza-se a cultura da heteronormatividade, dos papéis sociais modelados pela sociedade patriarcal.

Nos países desenvolvidos, a mobilização dos grupos identitários, de forma organizada, eclodiu na década de 1960. Nos Estados Unidos, por exemplo, ela desencadeou manifestações sociais exigindo a incorporação de um número maior de afrodescendentes no quadro funcional das organizações (CAPPELLIN e GIFFONI, 2007). 
No Brasil, foi somente em 1990 (ano da Lei n 8.078 - Código de Defesa do Consumidor) que setores do empresariado passaram a dedicar-se à questão da valorização da diversidade da força de trabalho. Diversos fatores influenciaram para isso, como os movimentos sindicais, as leis de cotas e as determinações contidas na Convenção $n^{0} 111$ da Organização Internacional do Trabalho, que proíbe quaisquer formas de discriminação (FLEURY, 2000).

As mulheres tiveram seu ingresso no mundo organizacional na década de 1920, mas no período de 1935 a 1968 ficou proibida a sua contratação, e somente em 1969 elas puderam reingressar através de concursos públicos (DEL PRIORE, 2010).

O pós-guerra, as mudanças econômicas, o acesso à educação e o novo modelo de núcleo familiar foram fundamentais para a grande inserção das mulheres no ambiente de trabalho, porém em carreiras ainda tidas como femininas.

Atualmente, apenas $18 \%$ das mulheres detêm títulos de graduação em ciências da computação, segundo Phumzile Mlambo-Ngcuka, diretora executiva da ONU Mulheres.

O recente programa da entidade Nações Unidas - ONU Mulheres, que visa a igualdade de gênero e o empoderamento das mulheres na sociedade, busca também a adesão das empresas para seus sete princípios, no qual as signatárias se comprometem no desenvolvimento de programas para a igualdade de oportunidades e a não discriminação das mulheres no ambiente corporativo. Entretanto, apesar desses movimentos no mercado, muitas mulheres chegam a posições gerenciais médias não ascendendo aos níveis mais altos de gerenciamento (CONNEL, 2015).

As pessoas LGBT (Lésbicas, Gays, Bissexuais, Transexuais, Travestis e Transgêneros) também enfrentam dificuldade na inserção no mercado de trabalho ao afirmarem sua orientação sexual ou identidade de gênero, apesar de a sociedade mostrar-se atualmente mais aberta e respeitosa.

Segundo pesquisa realizada pela empresa de recrutamento Elancers (http://www.redebrasilatual.com.br/trabalho/2015/05/mercado-de-trabalho-brasileiro-ainda-e-hostil-a-populacao-lgbt-indica-estudo-170.html), 38\% das empresas brasileiras não contratariam pessoas LGBT para cargos de chefia, por receio de ter sua imagem associada ao funcionário e, com isso, perderem clientes ou sua credibilidade ser abalada.

Segundo a Associação Nacional de Travestis e Transexuais, grande parte deles, diante do alto nível de rejeição nas entrevistas de emprego, acabam se prostituindo. De acordo com NARDI (2006), as discriminações ligadas à sexualidade e ao gênero são o produto de uma rede complexa de relações entre a desigualdade social, a cor da pele, o sexismo, a homofobia e o heterossexismo.

Diante do cenário da sociedade contemporânea, no qual encontramos cidadãos mais educados e críticos de seus direitos e deveres graças ao espaço democrático de diálogo que as Ouvidorias propuseram desde sua criação no Brasil, tendo como cerne dessa relação a Declaração Universal dos Direitos Humanos, que afirma que todos nascem livres e iguais em dignidade e em direitos, dotados de razão e de consciência, o que é portanto o marco para a conquista dos Direitos Individuais, trazemos a reflexão para quão diversos são ou estão os institutos de Ouvidoria.

Como se dá a equidade de gênero no que tange ao cargo de Ouvidor, nos setores públicos e privados? Há diferenças salariais em função do gênero ou orientação sexual do Ouvidor? O Ou- 
vidor está preparado para acolher, tratar e recomendar sanções e políticas quando de denúncias relativas a racismo, sexismo, homofobia e heterossexismo, seja na Ouvidoria Organizacional ou na Ouvidoria Externa (denúncias relativas ao posicionamento discriminatório nas campanhas de comunicação da empresa ou no atendimento presencial, atendimento por chat, mídias digitais, por exemplo)? O instituto de Ombudsman/Ouvidoria tem em seu corpo de funcionários representantes de minorias (LGBTs, Mulheres, Negros, PCDs)?

\section{JUSTIFICATIVA E FUNDAMENTAÇÃO TEÓRICA}

O Estado liberal moderno define homem e mulher como cidadãos iguais, mas o código sexual dominante define homem e mulher como opostos. Comumente ideias sobre a divisão do trabalho na vida familiar definem as mulheres como donas de casas e cuidadoras de crianças. Esse pensamento advém do modelo patriarcal em que os homens são uma classe de sexo dominante, o estupro uma afirmação do poder dos homens sobre as mulheres e a imagem das mulheres como midiáticas, passivas e estúpidas.

Ao longo dos séculos as forças colonizadoras tomavam os corpos das mulheres da mesma forma que a terra. Uma hierarquia gerada da fusão entre gênero e raça se tornou característica central da sociedade colonial, persistindo no mundo contemporâneo e dentro das organizações, onde a predominância do poder é ditada por homens, brancos, com maior poder aquisitivo. Esse modelo também estabeleceu os parâmetros da sociedade capitalista de consumo, que por consequência sempre desprivilegiou o elo mais vulnerável da cadeia, o cidadão comum, em favor das empresas em sua busca incessante por lucratividade, motivo da importância do estabelecimento de aparatos de proteção ao cidadão e da instalação de instâncias de mediação dessa relação.

A publicação Manual de Boas Práticas - Ouvidorias Brasil, da Associação Brasileira das Relações Empresa-Cliente, na página 74, dispõe que:

A Ouvidoria tem um aspecto de impacto social amplo e significativo e deve implantar ações e mecanismos que incentivem o exercício da cidadania e possibilitem ao administrador a capacidade de análise e alteração de procedimentos, não se restringindo a ter um desempenho correto e sim uma escuta privilegiada das críticas e sugestões formuladas pelos cidadãos. Tangibiliza a necessidade de mudanças nos procedimentos e normas, atuando como instrumento de cogestão da administração.

A abordagem sobre o poder de Michael FOUCAULT (1979) é cética quanto à ideia de que há uma agência unificada de poder na sociedade - ele situa que o poder é disperso e opera de forma difusa, gerando identidades e práticas comportamentais.

O poder é também tema central na opressão gay por meio da criminalização, da violência e de opressões culturais. As mesmas estatísticas que mostram as mulheres como alvos da violência doméstica, mostram gays como alvos mais comuns de outras formas de crime, normalmente cometidos por outros homens.

De acordo com FOUCAULT (1979), a modernidade trouxe duas novidades fortemente interligadas: poder disciplinar, no âmbito dos indivíduos; e sociedade estatal, no âmbito do coletivo. $\mathrm{O}$ 
poder disciplinar surgiu em substituição ao poder pastoral (no campo religioso). No poder pastoral, o pastor deve conhecer individualmente cada membro do seu rebanho, se sacrificar por ele e salvá-lo. No campo político, a sociedade estatal veio em substituição ao poder de soberania, o qual vem da lógica pastoral, embora não possa ser salvacionista, nem piedoso e nem mesmo individualizante. Assim, o poder de soberania tem um déficit em relação ao poder pastoral. Daí surge o poder disciplinar para preencher essa lacuna, com efeitos individualizantes, vigilante, a fim de preencher os espaços vazios do campo político, e, em geral, acaba por estabelecer a relação de modo negativo: rejeição, exclusão, recusa, barragem, ocultação e mascaramento.

A história da sexualidade, quando centrada nos mecanismos de repressão, supõe duas rupturas, uma no século XVII, com o nascimento das grandes proibições, a valorização exclusiva da sexualidade adulta e matrimonial, os imperativos de decência, a esquiva do corpo e os pudores da linguagem, e a outra no século XX, momento em que mecanismos de repressão começam a afrouxar, das interdições imperiosas a uma relativa tolerância com as relações pré-nupciais ou extramatrimoniais.

Essa abertura permite estudar como as pessoas adquirem o gênero e podemos notar que começam mudanças em um setor da sociedade, mesmo que lentamente.

Segundo SCOTT (1990), gênero é a caracterização de relações de poder, delimitadas historicamente e socialmente estabelecidas, a partir das diferenças sexuais biológicas, possibilitando a naturalização de características mais e menos valoradas dos papéis sociais masculino e feminino, respectivamente, gerando formas de dominação tais como discrepâncias socioculturais, numa constante dialética permeada pelas mais diversas representações simbólicas.

Há notória diferença entre os países a respeito do tema. Considerada uma violação dos direitos humanos desde 1991 pela Anistia Internacional, a discriminação contra o público LGBT ainda é algo muito preocupante: em alguns países, como o Irã, as relações homossexuais ainda são proibidas e puníveis com pena de morte, embora a transexualidade seja permitida e bem vista pelo governo.

Muitas são as discussões sobre a definição de gênero, uma vez que a vida humana não se divide apenas em duas esferas, nem o caráter humano em dois tipos, acima de tudo o gênero é uma questão de relações sociais e reconhecimento corporal. Na página 9 da cartilha Nascidos Livres e Iguais, da Organização das Nações Unidas (ONU), lê-se:

Após décadas em que as palavras "orientação sexual" e "identidade de gênero" eram raramente proferidas em encontros formais e intergovernamentais nas Nações Unidas, um debate se desenvolveu no Conselho de Direitos Humanos, em Genebra, sobre os direitos de lésbicas, gays, bissexuais e transgêneros. As discussões no Conselho focaram sua atenção política nas leis discriminatórias, nas práticas em nível nacional e nas obrigações dos Estados perante o regime internacional de direitos humanos, para enquadrá-las através de medidas legislativas e outras normas. Em junho de 2011, o Conselho adotou a resolução 17/19 - primeira resolução das Nações Unidas sobre direitos humanos, orientação sexual e identidade de gênero. A resolução foi aprovada por uma margem pequena, mas recebeu significativo suporte dos membros do Conselho de todas as regiões. Sua adoção abriu caminho para o primeiro relatório oficial das Nações Unidas sobre o assunto, preparado pelo Escritório do Alto Comissariado para os Direitos Humanos.

Entre os países, 94 apoiam o Conselho de Direitos Humanos, contra 54 países que assinaram a declaração de 2008 contra os direitos LGBT. 
No ambiente corporativo, o gênero molda as definições de funções, as compreensões de méritos, promoções, as técnicas de gerenciamento e o encarreiramento dos funcionários. A construção de uma visão potente que contribua para que as empresas invistam em inclusão passa por dois caminhos, o da economia inteligente e o do reconhecimento dos direitos e das realidades que, na origem, estimularam movimentos pela igualdade de gênero.

Ao longo dos anos, esses movimentos, no âmbito do trabalho, têm apontado para a necessidade de equidade salarial, engajamento de ambos, homens e mulheres, e empoderamento de mulheres em espaços de decisão etc.

Esse ambiente por vezes, quando não inclusivo e igualitário em oportunidades, é o cenário de conflitos entre líderes e liderados, onde mais uma vez estabelece-se a relação de poder e o domínio do mais forte frente ao tido "diferente".

Uma pesquisa publicada pela revista Você $R H$ afirma que apenas $29 \%$ das empresas preparam seus funcionários/líderes para treinamentos sobre diversidade; $30 \%$ das empresas não têm e não planejam estratégia sobre diversidade e inclusão; e outros 37\% afirmam que pretendem desenhar. Outros $47 \%$ das empresas na América Latina, segundo a pesquisa da consultoria americana CEB, focam a inclusão por aspectos legais e jurídicos.

LOURO (2003) mostra que as discussões sobre gênero têm por objetivo combater as relações autoritárias, questionar a rigidez dos padrões de conduta estabelecidos para homens e mulheres e apontar caminhos para a transformação dos paradigmas estabelecidos em torno da relação homens/mulheres na sociedade, o que nos possibilita repensar e discutir a participação social, estabelecendo novas relações entre a subjetividade do outro e a individual, respeitando as semelhanças e diferenças, mas acima de tudo propondo-se ao diálogo com essas diferenças.

SCOTT (1995) argumenta que as relações de gênero são marcadas por desigualdades, hierarquias e obediências, sendo estas nada mais que relações de poder, possuindo uma dinâmica própria, articulando-se através de outras formas de dominação e desigualdades sociais, como raça, etnia, classe, entre outros, legitimadas socialmente, constituindo-se em construções.

Os estudos foucaultianos $(1979,2007)$ defendem que o sujeito se constitui por meio de práticas discursivas, que se fazem por meio de processos de subjetivação, resultado de uma construção que se dá no interior de um espaço demarcado por três eixos: Ser-Saber; Ser-Poder; Ser-Ética.

As organizações investem cada vez mais recursos na formação e desenvolvimento dos seus funcionários e, consequentemente, os líderes de Recursos Humanos tentam reter os funcionários a todo o custo (ONGORI, 2007).

O instituto de Ouvidoria pauta-se por princípios de ética, imparcialidade, confidencialidade, neutralidade e independência, porém, inserido dentro dos sistemas públicos ou privados, o Ouvidor lida com as faces do poder, e o poder marca fronteiras, dita a lei em regime binário, permitido e proibido, lícito e ilícito. Ao longo dos séculos, conforme breve contextualização histórica, o poder permeia as nossas relações interpessoais, "herdamos" uma sociedade patriarcal, que influencia os costumes da sociedade contemporânea, os papéis, os vínculos familiares, a escola, os dogmas religiosos. Mas, também no ambiente corporativo, a opressão pelo poder torna o diverso à orientação sexual heteronormativa vigente objeto de intolerância, discriminação e com possibilidades não igualitárias de inserção ou crescimento profissional, como nas questões de gênero que, com raras exceções, 
não possibilitam às mulheres, por exemplo, os cargos de alta liderança nas empresas, podendo prejudicar também as nomeações aos cargos de Ouvidoria ou limitar sua autonomia, bem como viabiliza situações de assédios e pressões sofridas em decorrência do gênero ou orientação sexual.

A discriminação é a materialização de ações arbitrárias cuja gênese repousa no preconceito, ocorrendo através de ações comissivas ou omissivas, e que pode produzir a violação de direitos contra indivíduos ou grupos estigmatizados (RIOS, 2007).

O princípio de imparcialidade na prática do Ouvidor, no que concerne à análise das questões de Diversidade e Equidade de Gênero, pode sofrer influência dos seus vieses inconscientes, uma vez que somos guiados por vieses que não controlamos, tema explicado pela neurociência. A autora Regina MADALOZZO, na cartilha Vieses Inconscientes, Equidade de Gênero e o Mundo Corporativo, destaca cinco tipos de vieses inconscientes: viés de afinidade - é a tendência de avaliar aqueles que se parecem conosco; viés de percepção - quando as pessoas acreditam e reforçam estereótipos sem base concreta em fatos; viés confirmatório - é caracterizado pela prática em buscar informações que confirmem nossas hipóteses e o descarte de informações que confrontem nossas crenças; efeito halo - é a propensão de, com uma única informação positiva ou que nos agrade, avaliar o restante das informações de forma positiva também; efeito grupo - é a tendência de seguir o comportamento do grupo, para não desviar o padrão vigente.

Portanto, reconhecer que todos temos vieses inconscientes, refletir sobre eles e o impacto que podem causar, é fundamental na atividade do Ouvidor.

\section{METODOLOGIA}

Sugere-se investigar a existência de diversidade e equidade de gênero nos institutos de Ouvidoria no Brasil:

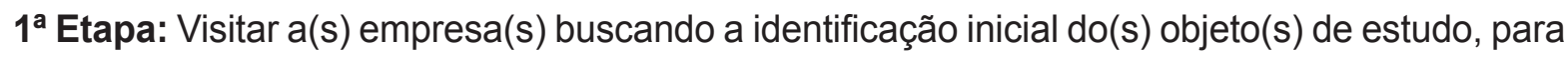
aplicação de questionário estruturado com perguntas quantitativas fechadas, identificação e caracterização dos Ouvidores (nesta fase serão avaliados dados objetivos, tal como: faixa etária, gênero, escolaridade, histórico profissional, cargo, remuneração).

$2^{\text {a }}$ Etapa: Submeter o questionário de pesquisa para apreciação do Comitê de Ética da Universidade.

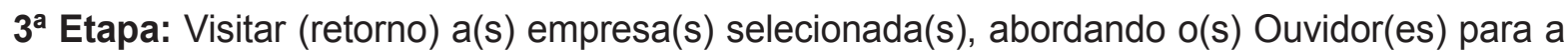
realização de entrevista aberta, visando uma análise aprofundada relacionada ao tema "diversidade e equidade de gênero" nos institutos de Ouvidoria no Brasil, para que expressem livremente anseios, vivências e até mesmo preconceitos sofridos.

4 ${ }^{a}$ Etapa: Analisar e tabular os dados, evidenciando-se a problemática.

5a Etapa: Elaborar e-book educacional sobre diversidade e equidade de gênero e educação sexual para Ouvidores. 


\section{RESULTADOS ESPERADOS E CONTRIBUIÇÕES}

A diversidade (do termo latino diversitate) está ligada aos conceitos de diferença, oposição, pluralidade, multiplicidade, diferentes ângulos de visão ou de abordagem, heterogeneidade, comunhão de contrários, intersecção de diferenças ou tolerância mútua, mas, apesar do tema ser amplamente discutido na sociedade atual, notamos que as oportunidades no mercado de trabalho e a ascensão profissional estão intimamente ligadas ao gênero e à orientação sexual do indivíduo, além de outros marcadores identitários.

O Ouvidor tão intimamente ligado aos Direitos Humanos e à Ética, mediador dos conflitos entre empresas e cidadãos, agente de transformação nos processos e políticas em seu segmento de atuação, público ou privado, necessita estar aberto e acompanhar as evoluções, como indivíduo, da sociedade contemporânea. O esclarecimento dos fundamentos da concepção de diversidade e gênero na educação sexual num contexto histórico social, bem como da subjugação pelo poder e a influência dos vieses inconscientes em suas análises e recomendações, devem fazer parte do arcabouço de formação do Ouvidor, uma vez que o preconceito coletivo organizacional por vezes é fruto da ausência de informação qualificada.

Nesse sentido, este artigo sugere um projeto de pesquisa sobre a diversidade e equidade de gênero nos institutos de Ouvidoria no Brasil, de forma amostral quantitativa e qualitativa e, a partir da análise dos dados obtidos, a elaboração de e-book educacional sobre diversidade e equidade de gênero e elaboração de curso presencial sobre educação sexual formal para Ombudsmen/Ouvidores, para que possam aprender a analisar os discursos como efeito de sentido entre interlocutores e, para condição de produção, circulação e recepção desses discursos, possam eleger estratégias discursivas que construam um ambiente de inclusão, tolerância, inovação e melhoria do ser humano nas suas relações pessoais e interpessoais.

Visando compartilhar com o segmento em questão os dados obtidos na pesquisa a ser realizada pelas autoras, através do Grupo de Estudos em Educação, Sexualidade, Tecnologias, Linguagens e Discursos - GESTELD do CTI/FEB/UNESP de Bauru - SP, eles serão publicados no ano de 2019, na Revista Científica da ABO - Associação Brasileira de Ouvidores/Ombudsman.

\section{REFERÊNCIAS}

AMARO, M. O diferente é igual. Você RH, n. 48, 2017.

CAPPELLIN, P. As desigualdades impertinentes. Revista Gênero, v. 9, n. 1, 2008.

CONNEL, R. Gênero - Uma perspectiva global. São Paulo: nVersos Editora, 2015.

DEL PRIORE. Pró-equidade de gênero. Revista Profi, 2010.

FLEURY, M.T. Gerenciando a diversidade cultural: experiências de empresas brasileiras. Revista de Administração de Empresas, v. 40, n. 3. 2000.

FOUCAULT, Michel. Microfísica do poder. Organização e tradução de Roberto Machado. Rio de Janeiro: Graal, 1979. 
. História da sexualidade 1. Tradução de Maria Thereza da Costa Albuquerque e J. A. Guilhon Albuquerque. Rio de Janeiro: Graal, 1998.

LOURO, G. L. Gênero, sexualidade e educação. Uma perspectiva pós-estruturalista. 5. ed. v. 1. Petrópolis: Vozes, 2003. $179 \mathrm{p}$

MEDAUAR, Odete. Controle da Administração Pública. São Paulo: Ed. Revista dos Tribunais, 1993.

NARDI, H. C. Youth subjectivity in Brazilian cultural an educational context. Journal of Gay and Lesbians Issues in Education, 2006.

RIOS, R. R. O conceito da homofobia na perspectiva dos direitos humanos e no contexto dos estudos sobre preconceito e discriminação. Porto Alegre: Livraria do advogado editora, 2007.

ONGORI, H. A review of the literature on employee turnover. Africa Journal of Business Management, 1(3), p. 49-54, 2007.

SCOTT, J. Gênero: uma categoria útil para a análise histórica. Recife: SOS Corpo, 1991. 71-99, 1995

Gênero: uma categoria útil de análise histórica. In: Revista Educação \& Realidade 2 (20), Porto Alegre, p. 